\title{
New Concept Air Conditioning System for the Operating Room to Minimize Patient Cooling and Surgeon Heating: A Historical Control Cohort Study
}

\author{
Hisashi Usuki $^{1,2} \cdot$ Hiroaki Kitamura $^{1} \cdot$ Yasuhisa Ando $^{2} \cdot$ Hironobu Suto $^{2} \cdot$ Eisuke Asano $^{2} \cdot$ \\ Minoru Ohshima $^{2}$ - Takayoshi Kishino ${ }^{2} \cdot$ Kensuke Kumamoto $^{2} \cdot$ Keiichi Okano $^{2}$. \\ Yasuyuki Suzuki ${ }^{2}$
}

Published online: 10 October 2019

(C) The Author(s) 2019

\begin{abstract}
Background Intraoperative hypothermia is a common adverse event. For avoiding the complication due to hypothermia, many warming devices and methods have been used in perioperative period. It has been reported that more patients undergoing laparoscopic surgery tend to have hypothermia than with open surgery. To avoid intraoperative hypothermia, many kinds of warming tools have been used. But, it was also reported that some warming methods increased perceptions of distraction and physical demand.

Methods To achieve both patients' normothermia and surgeons' comfort, new air conditioning (AC) system was designed with considering the characteristics of laparoscopic surgery. The temperature of the airflows to the patient and to the surgeons can be adjusted independently in this new system. The new system has two parts. One controls the temperature of the central area over the operation table. The air from this part falls on the patients. The other part is the lateral area beside the operating table; the air from this part falls on the surgeons. The subjects of this study were 160 gastric cancer patients and 316 colorectal cancer patients undergoing laparoscopic surgery. The temperature of the central flow was set $23.5{ }^{\circ} \mathrm{C}$, and the temperature of the lateral flow was set $22{ }^{\circ} \mathrm{C}$ just after the anesthesia. The number of timepoints the patient spent in hypothermic state, defined as a temperature cooler by $0.5{ }^{\circ} \mathrm{C}$ or more than that at the starting point of surgery, was determined in each patient.

Results In the results, the rate of hypothermic state in old operation rooms was $23.8 \%$ and that in new operation rooms was $2.7 \%$ in male gastric cancer patients $(p<0.01)$. And those were $37.1 \%$ in old operation rooms and $0.9 \%$ in new operation rooms in female gastric cancer patients $(p<0.01)$. The rate of hypothermic state in old operation rooms was $30.0 \%$ and that in new operation rooms was $9.5 \%$ in male colorectal cancer patients $(p<0.01)$. And those were $41.6 \%$ in old operation rooms and $8.9 \%$ in new operation rooms in female colorectal cancer patients $(p<0.01)$. The similar results were showed in the study, which subjects were limited the patients undergoing surgery in 2015 and 2016; which were the last year the old operation rooms were used and the first year the new operation rooms were used.

Conclusions Thus, the usefulness of the new air conditioning system for achieving both patients' normothermia and comfort of surgeons could be verified in this study.
\end{abstract}

Hisashi Usuki

usuki@kms.ac.jp

1 Surgical Center, Kagawa University Hospital, Ikenobe 1750-1, Miki, Kita, Kagawa, Japan
2 Department of Gastroenterological Surgery, Faculty of Medicine/Graduate School of Medicine, Kagawa University, Ikenobe 1750-1, Miki, Kita, Kagawa, Japan 


\section{Introduction}

Intraoperative hypothermia is a common adverse event. It was reported that more patients tended to have hypothermia among those undergoing laparoscopic surgery compared to those undergoing open surgery [1-3]. In laparoscopic surgery, a large area of the patient's skin is exposed to the room air, and it is difficult to warm the patient's body. The cold and dry carbon dioxide gas used to induce pneumoperitoneum is another likely cause of hypothermia $[1,2]$. One of the most important and overlooked problems, which is common with open surgery, is that there is often a discrepancy between the most comfortable temperature for the patient and that for the surgeons. During many surgeries, the patient is mostly naked and lying on an unheated operative table. A surgeon wears a surgical gown and faces rigorous mental and physical challenges involved in surgery. The temperature that is comfortable for the patient is often too hot for the surgeon, and thus, the surgeon may ask that the operating room (OR) temperature be lowered. This easily leads to hypothermia in patients, whose blood vessels are dilated by anesthetics.

For the precise control of patients' body temperatures while maintaining surgeons' comfort, a new concept air conditioning (AC) system was adopted in the newly constructed ORs at Kagawa University Hospital. In the present study, the body temperatures and the amount of bleeding of patients undergoing laparoscopic surgery in the new ORs with the AC system were compared with those of patients undergoing laparoscopic surgery in the 'old' ORs without the AC system in order to evaluate the effects and utility of the new AC system. OR nurses were interviewed about the surgeon's reports concerning the AC, as an evaluation of the surgeons' comfort.

\section{Patients and methods}

\section{Patients}

The subjects of this study were 160 gastric cancer (GC) patients and 316 colorectal cancer (CC) patients who underwent laparoscopic surgery in an OR at Kagawa University Hospital during the $>7$-year period from January 2011 to February 2018. The hospital's new ORs were completed at the end of December 2015. The patients who underwent surgery in either an old or new OR were the subjects of the first part of this study (Table 1).

In the second part of the study, the cases of only the patients who underwent laparoscopic surgery in 2015 (the last year of the old ORs) or 2016 (the first year of the new ORs) were examined. This more limited population was
Table 1 Patients underwent laparoscopic surgery (2011-2018)

\begin{tabular}{lll}
\hline Gastric cancer patients & 160 patients & $68.1 \pm 10.6$ years old \\
In old operation rooms & 107 patients & $67.8 \pm 10.3$ years old \\
Male patients & 73 patients & $68.7 \pm 10.0$ years old \\
Female patients & 34 patients & $65.9 \pm 10.5$ years old \\
In new operation rooms & 53 patients & $68.8 \pm 11.1$ years old \\
Male patients & 30 patients & $69.1 \pm 10.0$ years old \\
Female patients & 23 patients & $68.4 \pm 12.3$ years old \\
Colon cancer patients & 316 patients & $69.4 \pm 11.0$ years old \\
In old operation rooms & 206 patients & $69.0 \pm 11.2$ years old \\
Male patients & 115 patients & $68.7 \pm 10.8$ years old \\
Female patients & 91 patients & $69.3 \pm 11.8$ years old \\
In new operation rooms & 110 patients & $70.4 \pm 10.4$ years old \\
Male patients & 72 patients & $71.2 \pm 9.3$ years old \\
Female patients & 38 patients & $68.8 \pm 12.0$ years old \\
\hline
\end{tabular}

Ages are reported as mean $\pm \mathrm{SD}$

Table 2 Patients underwent laparoscopic surgery (2015-2016)

\begin{tabular}{lll}
\hline Gastric cancer patients & 49 patients & $69.7 \pm 11.9$ years old \\
In old operation rooms & 23 patients & $69.0 \pm 10.9$ years old \\
Male patients & 14 patients & $70.3 \pm 10.6$ years old \\
Female patients & 9 patients & $67.0 \pm 11.0$ years old \\
In new operation rooms & 26 patients & $70.4 \pm 12.8$ years old \\
Male patients & 14 patients & $69.6 \pm 11.2$ years old \\
Female patients & 12 patients & $71.3 \pm 14.3$ years old \\
Colon cancer patients & 105 patients & $70.1 \pm 11.7$ years old \\
In old operation rooms & 49 patients & $68.8 \pm 12.6$ years old \\
Male patients & 31 patients & $69.2 \pm 12.4$ years old \\
Female patients & 18 patients & $68.2 \pm 12.8$ years old \\
In new operation rooms & 56 patients & $71.2 \pm 10.9$ years old \\
Male patients & 35 patients & $72.0 \pm 7.4$ years old \\
Female patients & 21 patients & $69.8 \pm 14.9$ years old \\
\hline
\end{tabular}

Ages are reported as mean $\pm \mathrm{SD}$

selected to keep the surgical staff as consistent as possible (Table 2). This study was approved by the ethics committee of Kagawa University (approval no. 2017-014), and the requirement for informed consent was waived for this retrospective analysis.

\section{Patient position and warming tools}

All patients underwent the surgeries in the lithotomy position. Their chest and upper limbs were warmed using devices with warmed air bags. The backs of the GC patients were also warmed by a warm blanket, but the backs of the $\mathrm{CC}$ patients could not be warmed due to the use of a bodyfixing device for maintaining the Trendelenburg position 
during surgery. The intravenous fluid was not warmed [4]. No amino acid administrations were used on our patients [5-7]. The carbon dioxide gas for pneumoperitoneum was neither humidified nor warmed $[8,9]$.

\section{The new air conditioning system}

Each of the new AC systems set into the ceiling of the hospital's new ORs has a high-efficiency particulate air filter (HEPA filter) for infection control, as is common in ORs [10]. However, there is a key difference from previous operating room AC systems. The new system has two parts. One controls the temperature of the central area over the operation table; the airflow from this part of the AC falls on the patient. The other part is the lateral area beside the operating table; the AC's airflow for this falls on the surgeon(s). The temperatures of the airflow to the patient and the airflow to the surgeon can be adjusted independently. Thus, the patient on the operation table can be warmed by the central airflow and the surgeon can be cooled by the lateral airflow. The cost of the new AC system was $6.7 \%$ higher than that of the previous AC system used in the old ORs.

\section{Control of the airflows temperatures}

In the old ORs, the temperature of the airflow of the single AC system was controlled at $25^{\circ} \mathrm{C}$ before the patients were brought into the OR. After anesthesia was administered, the temperature was set at the temperature preferred by the surgeons. In the new ORs, the temperature of the airflows of both the central and lateral AC system was kept at $25{ }^{\circ} \mathrm{C}$ before the patients were brought into the ORs. Immediately after the induction of anesthesia, the temperature of the central flow was changed to $23.5^{\circ} \mathrm{C}$, and the temperature of the lateral flow was changed to $22{ }^{\circ} \mathrm{C}$. After that, the temperature of both airflows was controlled as directed by the surgeon.

\section{Sampling and computation of measured temperatures}

The body temperature of each patient was measured continuously by a sensor that was inserted into the bladder. The temperatures were archived in the anesthetic record automatically. The patient's body temperature just before the surgery and the body temperature every $10 \mathrm{~min}$ from 10 to $100 \mathrm{~min}$ after the start of surgery were recorded. The differences between the body temperature at the starting point of surgery and the body temperature at each 10-min checkpoint were calculated. The number of timepoints the patient spent in a hypothermic state, defined as a temperature cooler by $\geq 0.5{ }^{\circ} \mathrm{C}$ more than that at the starting point of surgery, was determined in each patient.

\section{Evaluation of body temperature}

The frequencies of the hypothermic state in the patients undergoing surgery in the old ORs (the 'old OR group') were compared with the frequencies in the new ORs (the 'new OR group'). The data of the patients who underwent surgery during the years from 2011 to 2015 were compared with those of the patients who underwent surgery from the beginning of 2016 to February 2018. The data of the patients who underwent surgery in 2015 (in the old ORs) were compared with the data of the patients who underwent surgery in 2016 (in the new ORs). Separate evaluations were performed for the male and female patients with either type of cancer (GC or CC).

\section{Bleeding}

The amount of bleeding in the operation period of all patients was extracted from the anesthetic records. The bleeding amounts of the old OR group were compared with those of the new OR group. The rate of patients receiving a blood transfusion was compared between the old and new OR groups.

\section{Interview regarding surgeons' assessments of the new AC system}

There were 46 nurses in the hospital's operative theater during the study period. For the present study, the chief nurse interviewed the OR nurses. She asked the nurses whether or not a surgeon had expressed any concerns or problems regarding the new AC system, during or after a surgery. The interview results were reported by the chief nurse to the study investigator.

\section{Statistical analysis}

The Chi-square test and Student's $t$ test were used to compare differences between patient groups and interview results.

\section{Results}

\section{The patients body temperature}

\section{Gastric cancer}

(1) The male GC patients

Ten timepoints per patient were used for the evaluation. However, in two patients who underwent surgery in an old $\mathrm{OR}$, the laparoscopic procedure was finished only $80 \mathrm{~min}$ 
Fig. 1 Rate of gastric cancer patients with hypothermic state in new operation rooms was less than that in old operation rooms

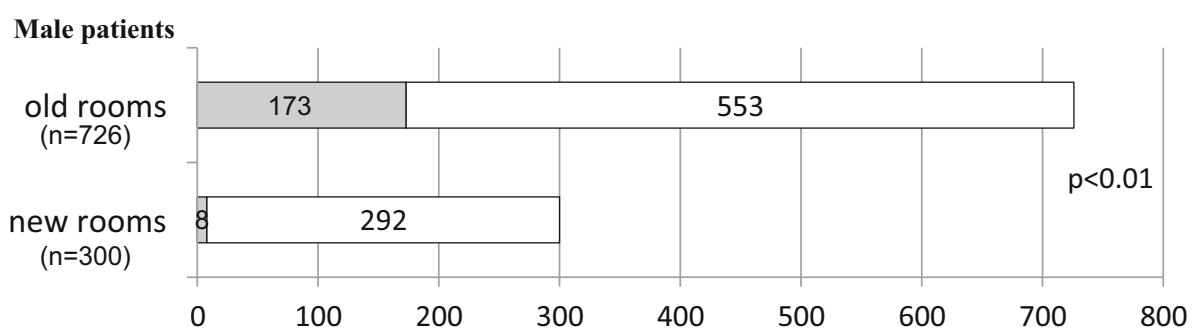

Female patients

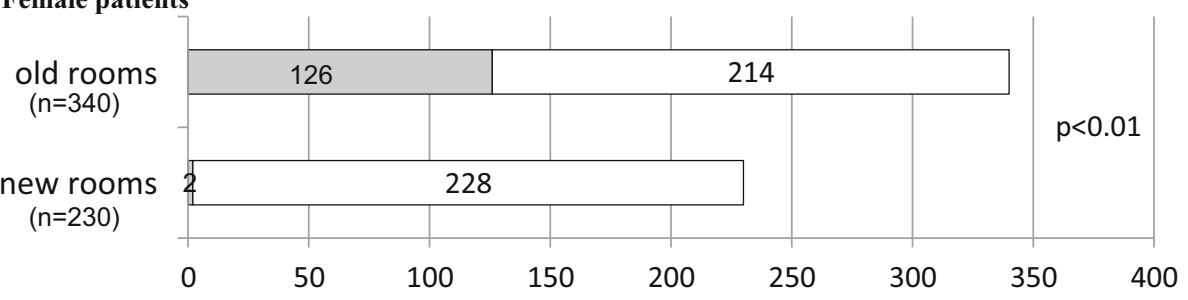

$\square$ hypothermia $\square$ normothermia

after the start of the surgery. Thus, there were 726 timepoints of the 73 male patients who underwent surgery for GC in the old ORs and 300 timepoints of the 30 male patients in the new ORs; for each timepoint, it was determined whether or not the patient's body temperature revealed that he was in a hypothermic state. The rate of hypothermic states among the male GC patients was $23.8 \%$ in the old OR group and significantly lower at $2.7 \%$ in the new OR group ( $p<0.01)$ (Fig. 1).

(2) The female GC patients

There were 340 timepoints for the 34 female GC patients who underwent surgery in the old ORs and 230 timepoints for the 23 female GC patients in the new ORs. The rate of hypothermic state was $37.1 \%$ in the old OR group and significantly lower at $0.9 \%$ in the new OR group $(p<0.01)$ (Fig. 1).

\section{Colorectal cancer}

\section{(1) The male CC patients}

In four of the male patients whose surgery for $\mathrm{CC}$ was performed in an old OR, the laparoscopic procedure lasted only 40, 60, 60 and $70 \mathrm{~min}$; among those whose surgery was in a new OR, there was one patient whose surgery lasted only $70 \mathrm{~min}$. Thus, there were 1133 timepoints of the 115 patients who underwent surgery in the old ORs and 717 timepoints of the 72 patients in the new ORs. The rate of hypothermic states was $30.0 \%$ in the old OR group and significantly lower at $9.5 \%$ in the new OR group $(p<0.01)$ (Fig. 2).

(2) The female CC patients
In five of the female patients whose laparoscopic surgery for $\mathrm{CC}$ was conducted in an old OR, the procedure ended only 40,60, 60, 60 and $90 \mathrm{~min}$ after the start of the surgery. Thus, there were 891 timepoints of the 91 female patients in the old ORs and 380 timepoints of the 38 patients in the new ORs. The rate of hypothermic states was high at $41.6 \%$ in the old OR group and significantly lower at $8.9 \%$ in the new OR group $(p<0.01)$ (Fig. 2).

\section{The patients' body temperatures in 2015 versus 2016}

The analyses of only the patients who underwent surgery in 2015 or 2016 revealed the following findings.

\section{Gastric cancer cases in 2015 ('old ORs') versus 2016 ('new ORs')}

\section{(1) The male GC patients}

There were 140 timepoints of the male GC patients in the old ORs (i.e., those used in 2015) and 140 timepoints of those in the new ORs (used in 2016). The rate of hypothermic states was $23.6 \%$ in the old OR group and significantly lower at $4.3 \%$ in the new OR group $(p<0.01)$ (Fig. 3).

(2) The female GC patients

There were 90 timepoints of the female GC patients who underwent surgery in the old ORs and 120 timepoints of those in the new ORs. The rate of hypothermic states was $27.8 \%$ in the old OR group and $1.7 \%$ in the new OR group $(p<0.01)$ (Fig. 3). 
Fig. 2 Rate of colorectal cancer patients with hypothermic state in new operation rooms was less than that in old operation rooms

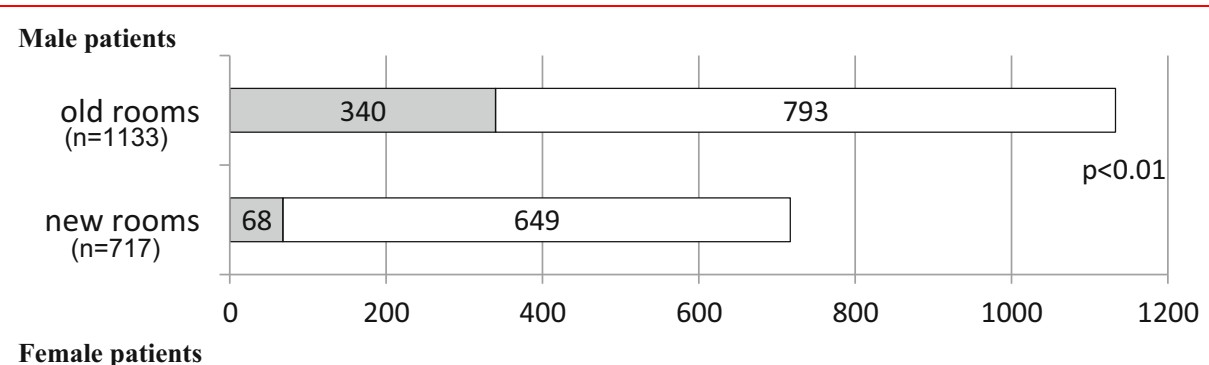

Female patients

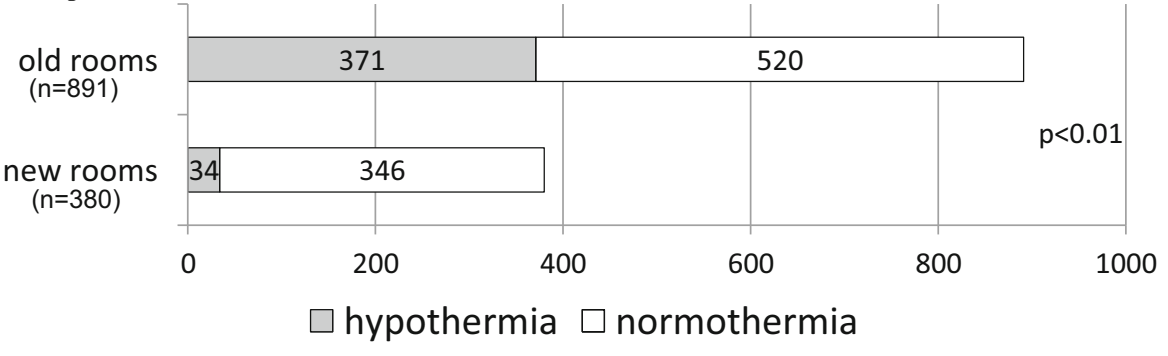

Fig. 3 Rate of gastric cancer patients with hypothermic state in new operation rooms was less than that in old operation rooms (2015-2016)

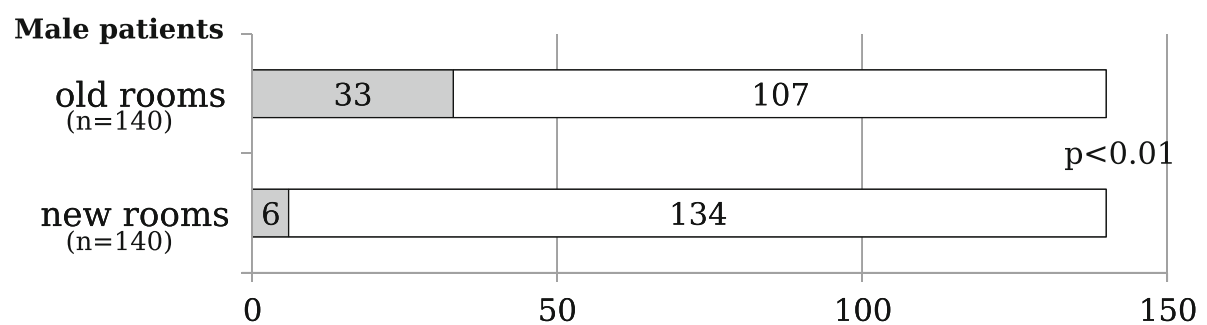

Female patients $\underset{(n=90)}{\text { old rooms }}$
new rooms
$(n=120)$

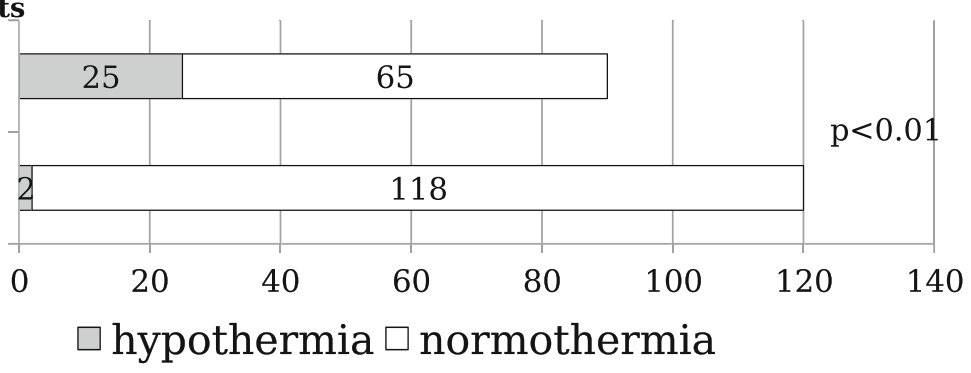

\section{Colorectal cancer}

(1) The male CC patients

There was one new OR patient whose laparoscopic surgery was finished only $70 \mathrm{~min}$ after the start of the surgery. There were thus 310 timepoints of 31 male CC patients undergoing surgery in the old ORs and 347 timepoints of 35 patients in the new ORs. The rate of hypothermic states was $25.2 \%$ in the old OR group and significantly lower at $10.4 \%$ in the new OR group $(p<0.01)$ (Fig. 4).

(2) The female CC patients

There were 180 timepoints of female CC patients who underwent surgery in old ORs and 210 timepoints of patients in the new ORs. The hypothermic rate was $20.6 \%$ in the old OR group and significantly lower at $11.0 \%$ in the new OR group $(p<0.01)$ (Fig. 4).

\section{Bleeding amounts}

\section{Gastric cancer}

The amount of bleeding of all of the old OR patients with GC was $100.5 \pm 122.3 \mathrm{~g}$ and that of the all of the new OR patients was significantly lower at $55.4 \pm 91.8 \mathrm{~g}$ $(p=0.02)$. There were three patients who received a blood transfusion in the old OR group, and none in the new OR group. 
Fig. 4 Rate of colorectal cancer patients with hypothermic state in new operation rooms was less than that in old operation rooms (2015-2016)

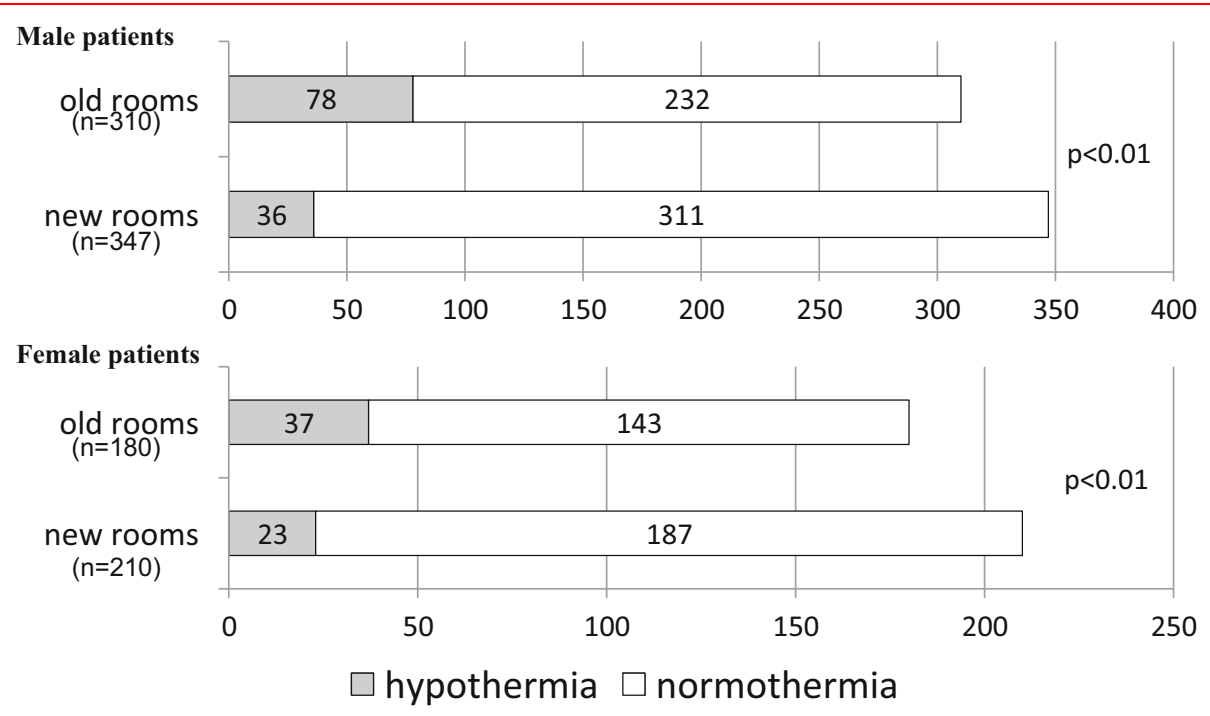

\section{Colorectal cancer}

The amount of bleeding of all of the old OR patients with CC was $137.2 \pm 329.0 \mathrm{~g}$, and that of all the new OR patients was $133.7 \pm 343.1 \mathrm{~g}$. This difference was not significant. Eight old OR patients and one new OR patient received a blood transfusion.

\section{Surgeons comfort}

None of the surgical nurses reported hearing any type of grievance from a surgeon regarding the new AC system for the ORs.

\section{Discussion}

Intraoperative hypothermia causes many complications. Patients with hypothermia tend to have delayed awakening from anesthesia [11]. The body's serum adrenalin level rises in the hypothermic state, and this causes a peripheral circulatory insufficiency and increases the risk of myocardial ischemia [12]. The hypothermic state augments blood loss and the transfusion requirement [13, 14]. Hypothermia was also reported to cause immunosuppression $[15,16]$ and to influence tumor growth and worsen the prognosis of cancer patients [3, 16]. Moreover, patients with intraoperative hypothermia tend to have more surgical site infections $[17,18]$, and the hypothermia affects patients' outcomes [5, 6, 17]. Thus, the 2017 US Centers for Disease Control (CDC) guidelines highly recommend that the intraoperative body temperatures of patients are adequately controlled [19].

Many approaches have been used in attempts to avoid patients' intraoperative hypothermia. The effectiveness of warmed intravenous fluid [4] and the usefulness of amino acid administration [5-7] have been described. The utility of patient prewarming before surgery has been studied [20, 21], and many types of warming tools have been used intraoperatively [22-24]. However, the area of skin surface warmed by such tools is much narrower in laparoscopic surgery than in open surgery, and warming tools are therefore not always effective for patients undergoing laparoscopic surgery. It was also reported that the warming tools did not influence surgeons' technical performance in short operative tasks, but the tools increased surgeons' perceptions of distraction and might influence their performance in long-duration operations [25]. The surgeons' comfort should thus be considered when testing warming tools and AC systems.

For the prevention of intraoperative hypothermia in patients while maintaining the surgeons' comfort, a new countermeasure was implemented at our hospital, i.e., a new AC system was installed in every OR after an initial investigation in an experimental room. To verify the merits of the new system, the present study determined the frequencies of the hypothermic state in patients undergoing laparoscopic surgery in the old and new ORs. Hypothermia has been defined as a body temperature 'lower than $36{ }^{\circ} \mathrm{C}$ ' [26]. In the present patient series, the body temperatures of the GC patients before surgery showed a $2.0^{\circ} \mathrm{C}$ difference (35.3-37.3 ${ }^{\circ} \mathrm{C}$ ) and that of the $\mathrm{CC}$ patients showed a $2.8^{\circ} \mathrm{C}$ difference $\left(35-37.8{ }^{\circ} \mathrm{C}\right)$. Thus, the precise effect of the $\mathrm{AC}$ system cannot be evaluated by using the absolute value of body temperature, and the hypothermic state was defined herein as a temperature cooler by $\geq 0.5^{\circ} \mathrm{C}$ compared to that at the starting point of surgery.

An earlier study at our hospital demonstrated that the patient's gender affects the body temperature of patients 
undergoing laparoscopic surgery [27, 28]. The reason for this phenomenon is that male patients have rich visceral adipose tissue protecting the mesenteric vessels from the cold carbon dioxide gas, whereas the visceral adipose tissue of female patients is much thinner. The frequencies of the hypothermic state of the males and females were thus evaluated separately in the present analyses.

The first part of this study revealed significant reductions in the frequency of the hypothermic state in the new ORs compared to the frequencies observed in the old ORs, suggesting the effectiveness of the new AC system. However, anesthesiologists and nurses in operation theaters often switch hospitals or change assignments within the hospital. It is undeniable that within the approximately 7-year study period, these changes could introduce significant differences in techniques that would affect the patients and the rate of hypothermia. Thus, only the GC and CC patients operated on in 2015 and 2016 at our hospital were selected for the second analysis, to exclude the influence of the turnover of staff in the operative theater to the greatest extent possible.

The difference in the amount of bleeding between the old OR and new OR groups among GC patients and the blood transfusion results may reflect the effect of the new AC system, but some surgeons switched hospitals during the study period. It thus cannot be declared that the new AC system is able to decrease the perioperative complication of hypothermia. Other complications such as anastomotic leakage were not examined, because these complications are more influenced by the technique of each surgeon, some of whom left the hospital.

The present results indicate that the new two-airflow AC system is useful for maintaining the body temperature of patients undergoing laparoscopic surgery. The effect of this system seems to be derived not only from the warm airflow for the patients but also from the cool airflow for the surgeons. The results of the nurse interviews revealed that none of the surgeons were dissatisfied with the new AC system. The reason for this result may be that with the new AC system, the surgeons can control the temperature of both airflows freely if they become uncomfortable. In other words, the surgeons were satisfied with the AC system by receiving the cool airflow, and lowering the temperature of the airflow on them will not lower the body temperature of the patients. Alternatively, even if the surgeons become too hot and lower the temperature of the 'surgeons' airflow,' the warm airflow for the patients prevents the patients' hypothermia. There was no instance of lowering the temperature of both airflows which would affect the patient's body temperature. The new AC system seems to be effective at keeping surgeons comfortable. The surgeons tended not to dictate the lowering of the temperature of the airflow to the patients. The concept of the new AC system in an OR has been to cool the surgeons rather than warm the patient. This is the most important point. The new twoairflow AC system provides a completely new method for warming patients in the OR.

In addition, the new AC system has some merits that are particular to laparoscopic surgery. In terms of the surgeons' posture during an operation, they stand erect in laparoscopic surgery so that only the laterally flowing cool airflow falls on them, whereas they tend to take a somewhat stooped or bent-over posture in open surgery such that some of the warm airflow would blow on their heads. In laparoscopic surgery, the surgeons are not influenced by the warm air falling on the patient, and they can maintain their comfort. The warm air falling on the patient is not obstructed by the surgeon's head. There is no need to use a surgical light in laparoscopic surgery, and thus, the warm air can fall on the patient's body directly.

Laparoscopic surgery has some demerits related to maintaining adequate patient body temperatures, including the patient's position for the surgery, the area of skin surface able to be warmed and the use of cold carbon dioxide gas $[1,2]$. However, laparoscopic surgery has some merits for the patients such as a surgeon's posture, the lack of the need for a surgical light and the warm airflow falling directly on the patient (when the new AC system is used). The number of laparoscopic surgeries is increasing dramatically, and the cost of the new AC system is not very high considering that it has clear benefits for both patients and surgeons and that its cost is a one-time investment at construction. Such AC systems should be introduced into all ORs used for laparoscopic surgeries.

There are several limitations to this study. The old ORs at our hospital were closed for reconstruction just after the completion of the new ORs, and thus, a randomized study could not be performed. The anesthesiologists and staff nurses in the new ORs were not exactly the same as those in the old ORs, even for the second part of the study. However, the occurrence of hypothermic states was greatly reduced in the new ORs. The usefulness of the new AC system was verified in this study.

Acknowledgements This work was supported by the JSPS KAKENHI, Grant No. 15K06323.

\section{Compliance with ethical standards}

\section{Conflict of interest No conflicts of interests or disclosures}

Open Access This article is distributed under the terms of the Creative Commons Attribution 4.0 International License (http://crea tivecommons.org/licenses/by/4.0/), which permits unrestricted use, distribution, and reproduction in any medium, provided you give appropriate credit to the original author(s) and the source, provide a link to the Creative Commons license, and indicate if changes were made. 


\section{References}

1. Huntington TR, LeMaster CB (1997) Laparoscopic hypothermia: heat loss from insufflation gas flow. Surg Laparosc Endosc 7:153-155

2. Kaynan AM, Winfield HN (2002) Thermostasis during laparoscopic urologic surgery. J Endourol 16:465-470

3. Nduka CC, Puttick M, Coates P et al (2002) Intraperitoneal hypothermia during surgery enhances postoperative tumor growth. Surg Endosc 16:611-615

4. Campbell G, Alderson P, Smith AF et al (2015) Warming of intravenous and irrigation fluids for preventing inadvertent perioperative hypothermia. Cochrane Database Syst Rev. https://doi. org/10.1002/14651858.CD009891.pub2

5. Sellden E, Lindahl SG (1999) Amino acid-induced thermogenesis reduces hypothermia during anesthesia and shortens hospital stay. Anesth Analg 89:1551-1556

6. Umenai T, Nakajima Y, Sessler DI et al (2006) Perioperative amino acid infusion improves recovery and shortens the duration of hospitalization after off-pump coronary artery bypass grafting. Anesth Analg 103:1386-1393

7. Fujita T, Okada N, Kanamori J et al (2017) Thermogenesis induced by amino acid administration prevents intraoperative hypothermia and reduces postoperative infectious complications after thoracoscopic esophagectomy. Dis Esophagus 30:1-7

8. Bashirov E, Cetiner S, Emre M et al (2007) A randomized controlled study evaluating the effects of the temperature of insufflated $\mathrm{CO}_{2}$ on core body temperature and blood gases (an experimental study). Surg Endosc 21:1820-1825

9. Dean M, Ramsay R, Heriot A et al (2017) Warmed, humidified $\mathrm{CO}_{2}$ insufflation benefits intraoperative core temperature during laparoscopic surgery: a meta-analysis. Asian J Endosc Surg 10:128-136

10. Miller-Leiden S, Lobascio C, Nazaroff WW et al (1996) Effectiveness of in-room air filtration and dilution ventilation for tuberculosis infection control. J Air Waste Manag Assoc (1995) 46:869-882

11. Leslie K, Sessler DI, Bjorksten AR et al (1995) Mild hypothermia alters propofol pharmacokinetics and increases the duration of action of atracurium. Anesth Analg 80:1007-1014

12. Hannan EL, Samadashvili Z, Wechsler A et al (2010) The relationship between perioperative temperature and adverse outcomes after off-pump coronary artery bypass graft surgery. J Thorac Cardiovasc Surg 139:1568-1575

13. Schmied H, Kurz A, Sessler DI et al (1996) Mild hypothermia increases blood loss and transfusion requirements during total hip arthroplasty. Lancet 347:289-292

14. Winkler M, Akca O, Birkenberg B et al (2000) Aggressive warming reduces blood loss during hip arthroplasty. Anesth Analg 91:978-984

15. Beilin B, Shavit Y, Razumovsky J et al (1998) Effects of mild perioperative hypothermia on cellular immune responses. Anesthesiology 89:1133-1140
16. Ben-Eliyahu S, Shakhar G, Rosenne E et al (1999) Hypothermia in barbiturate-anesthetized rats suppresses natural killer cell activity and compromises resistance to tumor metastasis: a role for adrenergic mechanisms. Anesthesiology 91:732-740

17. Kurz A, Sessler DI, Lenhardt R (1996) Perioperative normothermia to reduce the incidence of surgical-wound infection and shorten hospitalization. Study of wound infection and temperature group. N Engl J Med 334:1209-1215

18. Kurz A (2008) Thermal care in the perioperative period. Best Pract Res Clin Anaesthesiol 22:39-62

19. Berrios-Torres SI, Umscheid CA, Bratzler DW et al (2017) Centers for disease control and prevention guideline for the prevention of surgical site infection, 2017. JAMA Surg 152:784-791

20. Wong PF, Kumar S, Bohra A et al (2007) Randomized clinical trial of perioperative systemic warming in major elective abdominal surgery. Br J Surg 94:421-426

21. Erdling A, Johansson A (2015) Core temperature-the intraoperative difference between esophageal versus nasopharyngeal temperatures and the impact of prewarming, age, and weight: a randomized clinical trial. AANA J 83:99-105

22. Brandes IF, Muller C, Perl T et al (2013) Efficacy of a novel warming blanket: prospective randomized trial. Der Anaesthesist 62:137-142

23. Madrid E, Urrutia G, Roque i Figuls M et al (2016) Active body surface warming systems for preventing complications caused by inadvertent perioperative hypothermia in adults. Cochrane Database Syst Rev 4:Cd009016

24. Su SF, Nieh HC (2018) Efficacy of forced-air warming for preventing perioperative hypothermia and related complications in patients undergoing laparoscopic surgery: a randomized controlled trial. Int J Nurs Pract 24:e12660

25. Berg RJ, Inaba K, Sullivan M et al (2015) The impact of heat stress on operative performance and cognitive function during simulated laparoscopic operative tasks. Surgery 157:87-95

26. National Collaborating Centre for N, Supportive C, National Institute for Health and Clinical Excellence: Guidance (2008). In: The management of inadvertent perioperative hypothermia in adults. Royal College of Nursing (UK) National Collaborating Centre for Nursing and Supportive Care, London

27. Usuki H, Koizumi M (2017) The body temperature in laparoscopic surgery and the countermeasure in the construction of operative center. Jpn J Oper Med 38:100-106

28. Usuki H, Asano E, Oshima M et al (2018) Operating room: which temperature is comfortable for both patients and surgeons? Thermol Int 28:3

Publisher's Note Springer Nature remains neutral with regard to jurisdictional claims in published maps and institutional affiliations. 